\title{
IT Tools and Performance Indicators: A Qualitative Overview of Managerial, Organizational, Financial Strategies within Healthcare Sector
}

\author{
Marco Remondino ${ }^{1}$ \\ ${ }^{1}$ Department of Economics, University of Genoa, Italy \\ Correspondence: Marco Remondino, Department of Economics, University of Genoa, Italy. E-mail: \\ marco.remondino@economia.unige.it
}

Received: November 19, 2019

Accepted: December 20, 2019

Online Published: January 16, 2020

doi:10.5539/ijbm.v15n2p105

URL: https://doi.org/10.5539/ijbm.v15n2p105

\begin{abstract}
The work examines the different healthcare contexts in which innovation has been applied, or could be applied, resulting in cost containment and increased quality and efficiency of medical care services. In addition, the different factors influencing the adoption of information technologies in the national healthcare systems of the European Union are discussed, in particular as regards the existence of structural barriers. Innovation is defined as the creation of something still not existing, to be uses for new products and services or for more efficient processes and is therefore linked to change, because innovation requires change.

Information technology (IT) is described as the acquisition, processing and storage of data by a computing product. This work qualitatively analyses use cases, which are in turn based on quantitative research methodologies (i.e. performance indicators), commonly based on the manipulation of independent variables to generate statistically analyzable data, which guarantees objectivity and provides greater data reliability.

Studies have been conducted to observe current trends in access to information technology across different age groups, to detect the existence of correlations between Internet users and online healthcare information searches. In this work, several Italian initiatives for the diffusion of IT applications in the healthcare sector have been analyzed. Some of the ongoing pilot projects include the collaboration of the Politecnico di Milano, through the establishment of the Laboratory of Biomedical Technologies (TBMLab), and the Scuola Superiore Sant'Anna of Pisa, to carry out research on eHealth activities and to promote the development of home automation systems for patients with disabilities. The HHC-MOTES model should also be noted, which aims to analyze the implementation of IT in the healthcare (HHC) sector from the point of view of sustainability in the management, organizational, technological, environmental and social fields (MOTES).
\end{abstract}

Keywords: key performance indicators, database, management, organization, finance, strategies, healthcare

\section{Introduction}

Public and private business organizations have realized that there is an urgent need for ongoing assessments of their activities and processes, as markets are going through a long period of global recession, both to better monitor policy progress and to learn from previous challenges and experiences (Ferlie, Fitzgerald, and Pettigrew 1996; Kerzner 2019). An increasing number of institutions are currently considering how information systems can help them achieve their goals. Before considering whether to adopt a certain innovative technology, organizations should rely on cost-benefit analysis, especially when a radical redesign of the process is needed (Chen et al. 2016).

Innovation is considered to be one of the essential elements for any organization, whether operating in the public or corporate sector, that is seeking to succeed (Noe et al., 2017; De Vries, Bekkers, \& Tummers 2016). If a critical, perhaps exogenously determined situation arises, a way to deal with it is to drive change. In addition, the European Commission's recent strategies attribute to innovation and information technologies as a means by which current economic challenges can be overcome (Bryson 2018; Carayannis, Meissner, \& Edelkina, 2017). It is therefore important to learn how to manage change by addressing it in a structured way, guiding individuals and organizations in the transition processes of change (Remondino, 2005). The use of performance measurement indicators is essential for the evaluation of activities and for determining the most efficient actions 
needed to achieve the desired objectives (Remondino \& Boella, 2010; Remondino, 2018).

The application of innovative technological products such as CAD/CAM techniques (Ahlholm et al., 2019), combined with the use of integrated systems for virtual design and computerized production processes of public and corporate enterprises, have led entire industrial districts to increase their skills and services, achieving economies of scale through greater flexibility in working practices and a faster exchange of information between suppliers. Also the organizations operating within healthcare sector could have similar benefits.

The wording "information and communication technologies" (ICT) adds another dimension to IT, by integrating telecommunications, together with computers and data management software, used to allow users to store, manipulate and transmit information from one point to another (Lu, 2017; Tony et al., 2018).

There are several sources from which innovation can arise, some resulting from individual creative efforts such as inventions, others generated by users of certain technologies in search of solutions that can better adapt to their needs. The sources of innovation can be multiple, external or internal to the organisation, depending on whether activities are managed by internal research and development (R\&D) departments, by external sources such as universities or through liaison offices specifically created to promote the transfer of computer applications to markets (Tidd \& Bessant, 2018; Valverde, Nadeau, \& Scaravetti 2017).

Further sources have been identified in collaborative networks, i.e. of different organizations operating in similar markets or sectors, which have already developed core competencies, or already excel in some areas of business, but are willing to exchange information effectively, and complement R\&D efforts to increase knowledge and further improve, especially in highly technological markets where individual innovations have rarely been initiated due to the complexity of cost-benefit assessment methods and costly resources required for the implementation of such systems (Birkinshaw, Zimmermann, \& Raisch, 2016; Laakkonen, Hujala, \& Pykäläinen, 2019).

One of the biggest challenges for managers and business administrators is, in fact, to have valid tools to effectively manage resources, coordinate services, share ideas, knowledge and know-how within an organization, but not only, or within interconnected institutions, in order to adequately respond to social needs (Akter et al., 2016). IT systems are considered particularly useful to administrators in helping them make sense of the huge amount of data that are collected every day by business organizations, to manage their operations. However, assessments of IT implementation in business practices require organizations to rethink their working methods, sometimes through a thorough review of activities and processes that seem obsolete and no longer meet future expectations. These changes that require a radical redesign of working habits are called business process redesign (BPR). Examples of business process redesign include the radial reappraisal of decision-making and board roles, the acquisition and eventual removal of business functions, and the adoption of a new BPR (Broadbent, Weill, \& St. Clair, 1999; Short \& Venkatraman, 1992).

Families are witnessing to a steady growth in the use of ICT systems in recent years. The share of families owning personal computers has increased over time, as has access to the Internet. In more developed regions, the use of web-based applications has gained considerable acceptance in recent years, especially with regard to broadband infrastructures that have allowed faster and wider access to information. Despite the rapid increase in Internet users, Italy is still in a low position among the other countries of the European Union. Measuring the percentage of households with at least one member aged 16 to 74 having access to the Internet, Italy ranks 22nd with an adoption rate of 62 per cent, while the European average is 73 per cent (Vicente \& López, 2011; Cruz-Jesus, Oliveira, \& Bacao, 2012).

With regard to healthcare, studies (Lemire et al., 2008; Lustria, Smith, \& Hinnant, 2011) have been conducted to observe current trends in access to information technology among different age groups, to detect the existence of correlations between internet users and online health information searches. A survey conducted by BMC provides evidence of the links between the age of internet users and the use of health-oriented information on the Internet (Renahy, Parizot, \& Chauvin, 2008; Sheng \& Simpson, 2013). The results are shown in Figure 1.

The use of technology in medicine began with the introduction of computer systems. Several specialized university departments have been created in different European countries, to gain a greater knowledge and understanding of the benefits and opportunities of computer applications in the field of healthcare. Information technology is believed to have the potential to significantly increase the efficiency of the healthcare sector by helping providers better manage information (De Gagne et al., 2012).

From an international perspective, their use has been a massive use of the latest computerized applications within intensive care units (ICUs), for monitoring patients' vital signs and automatically sending alerts to doctors, 
nurses or other healthcare professionals in the event of an emergency. The spread of these innovations has enabled hospitals to significantly increase the quality of service offered to the population (social benefits), through highly affordable products. From this perspective, it is possible to imagine that an even wider adoption of different IT products and innovative telematic services could further expand the offer of healthcare goods, at the same time improving the perception of the quality of care service by users, through highly efficient process solutions (efficiency and cost containment) (Vincent \& Singer, 2010; Lagu et al., 2011; Namachivayam et al., 2010).

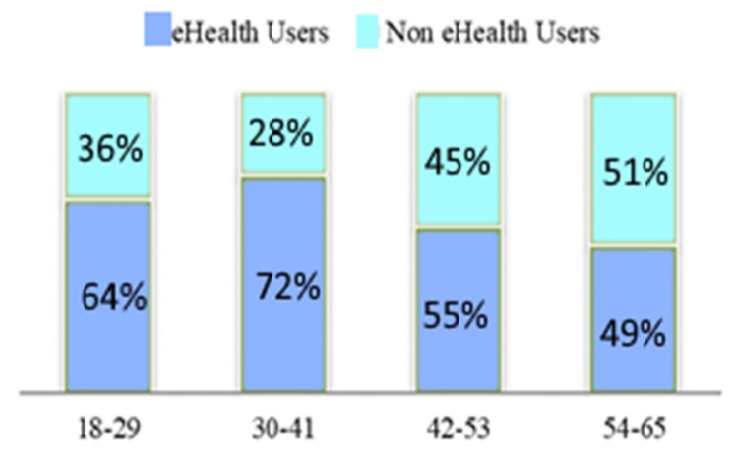

Figure 1. A correlation of Internet searches about eHealth with age

\section{Healthcare System Overview}

Healthcare is defined as the set of public health functions and corporate medical services, while healthcare systems include the set of various activities guided by a common objective in principle, namely the improvement of health outcomes for all the stakeholders in the healthcare chain through the supply of medical services (Turnock, 2012).

National healthcarecare systems can be funded with public participation, with reference to the involvement of national or regional governments or, alternatively, they could be managed by private organizations such, for example, insurance companies. Market-based systems are widely used in the United States and rely primarily on individual private healthcare insurance to finance services, while tax-funded systems use general tax revenues to finance healthcare and are more frequently operated by national and regional governments. The aim of tax-funded systems is to enable all citizens to have equal access to healthcare services as they contribute directly to paying for the services they provide. These universal healthcare systems are largely adopted both in European Union and in Canada (Saltman \& Figueras, 1998).

If the allocation of resources is determined by market forces, the result is as close to fully competitive markets as possible (Baumol, 1986). However, most healthcare systems are characterized by broad participation of national and regional governments, as in most developed countries no market functions perfectly. When compared to private organizations, public institutions usually have more responsibilities. Therefore, they tend to fight harder for the appropriate application of contractual provisions, in order to avoid any kind of opportunistic behavior that could be harmful to the Community (Simonazzi, 2008). For this reason, performance indicators are very important to derive an overall scenario of health outcomes and to provide benchmarking opportunities to rationalize resources in relation to the context in which organizations operate (Leandri, 2001; Börsch-Supan et al., 2013). It is the task of public healthcare organizations to plan and define strategies that maximize the productivity of resources, respond adequately to the population's needs, assign correct levels of priority to projects and action plans, provide for the development of new services or decide to redesign inefficient ones, ensuring high levels of quality to citizens. Unlike private companies, public enterprises are required to operate in a cost efficient way while not necessarily pursuing profit, because for them profit is not an objective to be achieved, but rather a feature that helps organizations to achieve their goals (Steiss, 2019; Organization, 2006).

The healthcare systems of the EU countries reflect a variety of different approaches, each of which sets out its own particularities. Therefore, a comparative study of these individual peculiarities of the various systems can facilitate the process of mutual learning to improve the overall outcome of healthcare (Rabin \& Charro, 2001; Fenger, 2007).

EU countries are orienting their strategies on innovation of healthcare processes, as it is believed to be essential 
for the improvement of outcomes (Grol et al., 2007). The scope is to react to the recession we are experiencing by seeking more efficient solutions in delivering healthcare, at an affordable cost, possibly orienting markets towards the introduction of innovative services for the treatment of patients in need.

To this regard, healthcare policy makers are aware of the gap that Europe has in the application of IT, and therefore, has agreed to set common eHealthcare strategies to foster gap reduction within EU countries by promoting ICT-based systems. EU countries have arranged to share their experiences in IT for better healthcare management (Torchia, Calabrò, \& Morner, 2015), which may help stimulate the growth of a new promising industrial sector and improve the quality of medical treatments and therapies within the European area. The main objectives pursued by European eHealth Action Plans relate to the creation of interoperable IT systems such as Electronic Health Records (EHR) or Electronic Medical Records (Ben-Assuli, 2015; Garrido et al., 2005; Hillestad et al., 2005; Hripcsak \& Albers, 2012; Jensen, Jensen, \& Brunak, 2012). These objectives are remarked in almost all national healthcarecare strategies within the EU, but seldom they are properly defined as few countries have fully been able to developed a complete electronic health information management system. Yet European countries are struggling to set and define common standardized protocols for the establishment of interoperability among different care providers, as a consequence of the many different individual approaches and structural configurations that each participating country developed for the delivery of healthcare practice.

The Italian National healthcarecare System is characterized by being complex, accounting on many procedures, and by long waiting lists (Ferré et al., 2014). It is believed that the use of Internet may potentially help re-design the system in order to improve healthcare and increase outcomes. One of the first problems encountered in IT use in Italy is related to legislation, because in Italy the sale of medication or drugs through internet is prohibited, as there is no way to control consumption and online prescriptions yet. Nevertheless, current legislation allows citizens to ask for second medical opinions via internet, as patients with diagnostic results may look for confirmation of prognosis given. But the use of this service is still relatively scarce, as user's awareness of the availability of existing services is still low, and in addition, it also depends on the regional strategies and investments made in eHealthcare services.

eHealthcare strategies in Italy are affected by responsibilities and valuable roles that have been attributed to the Regions, and been actualized in the constitutional reform of 2001 (Constitutional Law no. 3 of 18 October 2001). By the year 2000, the government promoted a fiscal federalism which attributed greater powers and autonomy to Regions. Having a national healthcarecare system funded by a central government and managed locally by regional authorities is undoubtedly a step forward as it provides different benefits to the system. In fact, local governments should have a better knowledge of the territory, of the risks and threats, as well as the type of diseases most frequently treated. This enables healthcare institutions to acquire best suited technologies to fulfill particular health needs of a specific geographical area, and targeting purchases over drugs and products which result more requested from statistical analysis.

There are however drawbacks to fiscal federalism related to the considerably dissimilar monitoring systems set for the monitoring of quality standards at local levels, which differ from region to region. In searching for a solution to this, Regions along with the Ministry of Health and Innovation have agreed to operate jointly in carrying out common interoperable eHealthcare strategies through a State-Regions board, placing particular focus in the deployment of interoperable electronic applications such as telehealthcare services for patients.

There are several Italian initiatives working towards IT application deployment in healthcare. Some of the ongoing pilot projects involves the cooperation of the Polytechnic Institute of Milan, through the establishment of TBM-Lab, and the Scuola Superiore Sant'Anna of Pisa (Nuti, 2010; Nuti, 2008), to carry out research on eHealth activities, and to promote the development of home automation systems of patients with disabilities. These projects are funded by the EU and by some local authority with the objective to foster the formation of technology clusters which would facilitate the creation of innovation competence and expertise within organizations to enhance competitiveness.

Last but not least, HHC-MOTES model comprises a set of metrics to evaluate and the sustainability of IT projects within healthcare, in different areas (economic, environmental and social) (Remondino, 2018).

\section{Performance Indicators in Healthcare}

Through the use of indicators (Boella \& Remondino, 2010; Fuller, 1997; Kim \& Huynh, 2008), it is possible to measure the degree into which objectives are met, changes happen, and effects are obtained, as indicators bring about quantified information useful for supporting decision-making processes. Being able to make data comparisons on strategies and performance results of different healthcare institutions at a regional, national and international level, is accredited as being the essential element for identifying internal system weaknesses and 
threats, and define the most appropriate strategies to improve outcome (Fuller, 1997).

Considering that latest market settings drive players to the promotion of collaborative approaches in spite of greater competitiveness, this leads to require healthcare institutions to equip themselves with key performance indicators (KPI) in order to benchmark activities and make comparisons of results, to evaluate the need to carry out corrective actions to previously set strategies. In addition, relying on KPI parameters activates learning processes that guide to the acquisition of best practices (Shohet, 2006).

Researchers have shown (Nuti, 2008) that countries presenting fragmented control of their national healthcarecare system, as well as having each provider pursue individual objectives, is obviously a consequence of having a negligible degree of integration, low information sharing levels, and a diminished adoption of healthcare IT systems, which in terms of KPI leads to poor and insufficient service levels. These observations emphasize the relevance of cooperation among stakeholders of the healthcare chain such as governments, institutions, hospitals, physicians, employers, pharmacies, consumers, and other healthcare subjects, to work towards the achievement of common objectives to increase chances of success.

Nevertheless, empirical evidence illustrates the existence of a highly compartmentalized evolution of technological progress in Italy, occasionally presenting isolated and individual innovative solutions to medical treatment, while the recent strong existing competition within IT industries is unintentionally leading to the creation of an aggregate emergent effect similar to that generated by economies of scale, driving down costs of high-tech products and services, and making them handier and more affordable than ever.

The Laboratory Management and Scuola Superiore Sant'Anna of Pisa (Nuti, 2010; Nuti, 2008) worked to define a new multi-dimensional set of KPI of healthcare, initially adopted by the Tuscan Region, and later expanded to other Regions such as Valle d'Aosta, Liguria, Piedmont, Marche, Umbria, Basilicata. It has also been integrated in the public administration of Bolzano and Trento.

The model identified different macro-dimensions of KPIs used by the Italian healthcare system within the network of Regions' project, which considers the evaluations of population health status, social welfare, as well as operational efficiency and financial and economical assessments.

It is noteworthy to mention that benefits tend to increase as KPIs currently adopted by the aforementioned Italian regions were to be spread at a national, or even better at an international level, reaching standardized methodologies and parameters for evaluation of performance results, and enabling benchmarking opportunities.

The collection of information (through databases) over the major death causes of a given nation appears to be an important factor for assessing if heath strategies adequately respond to citizen's needs. For this reason, improvements in population health status represent one of the major goals of healthcare systems. In order to gain information over the health status of a population it is necessary to analyze and measure mortality levels. Some specific indicators identified by the Scuola Superiore Sant'Anna of Pisa include infant mortality, mortality from cancer, mortality from cardiovascular disease, suicide rates, life expectancy at birth as well as citizen's lifestyles.

Most recent improvements in infant mortality rates by EU countries can be attributable to greater investments in healthcare by individual governments, along with cooperative efforts undertaken to promote the development of integrated programs and technologies, that increase life expectancy of newborns. In fact, the use of more sophisticated technologies allowed organizations to find new precious diagnostic practices and techniques that were successful for prevention purposes and treatment of various types of congenital malformations, thus limiting risk factors that newborn and premature babies can run into.

The objective of this indicator is to acquire information over the quality, appropriateness, efficiency of the service, as well as of management capabilities of institutions to effectively meet citizen's health needs. Indicators used to measure social and health data are attained by healthcare resource utilization rates, diagnosis and treatment practice for outpatients, which is useful for determining the degree of access to care services from citizens.

Resource allocation is a valuable indicator in evaluating quality of healthcare services, as the lack of necessary resources, whether it be of human species or referred to equipment, products or services, determines reductions in equity and access to care. However, allocation of healthcare resources may differ considerably depending on the utilization rates of the services throughout EU countries.

The Commonwealth Fund is a private foundation established in the U.S. for the promotion of high performance healthcare systems to elevate common good. In order to do so, the Commonwealth Fund relies on the use of various KPIs to measure, analyze and evaluate the performance of healthcare systems, detecting inefficiencies and supporting providers with valuable instruments to help them arrange for most appropriate healthcare 
strategies. The most important KPI parameters adopted by the Commonwealth Fund are identified in equity and access to care, avoidable hospital use and costs, prevention and treatment programmes, as well as healthy lives indicators including smoking, obesity, alcohol abuse and other factors that affect the longevity of the population.

Socio-demographic factors appear to be somehow correlated to healthcare performance, as data from the 2009 Commonwealth Fund State Scorecard showed sensible variations in KPIs between different states, referred to healthcare. In fact, states where adult consumption of tobacco and alcohol was higher, reported having also a greater number of hospital admission rates. Moreover, states with lower performance results presented higher cases of child obesity, emergency room visits among adult asthmatics, and nursing home requests. Even poverty seems to have consequences in health performance due to its relationship with the availability of innovative and technological resources, as well as other factors that may influence the accessibility of healthcare services to a population.

The Commonwealth Fund State Scorecard was largely requested by physicians as well as hospital systems, not just for the overall improvements of care, but to mind a wider and more integrated multi-stakeholder business to better control cost initiatives, increase quality of care, supply providers with feedbacks and emerging best practices.

Researchers have shown that countries presenting fragmented control of their national healthcarecare system, and have each provider pursue individual objectives, is a consequence of having a negligible degree of integration, low information sharing levels, and a diminished adoption of healthcare IT systems, which, as already stated, in terms of KPI leads to poor and insufficient service levels. These observations emphasize the relevance of cooperation among healthcare stakeholders such as governments, institutions, hospitals, physicians, employers, pharmacies, and consumers, to work towards the achievement of common objectives, that is to improve medical practice.

It is noteworthy to mention that Italy's healthcare system reports among the highest values of resources and utilization rates compared to other EU countries. The adoption of new technologies and ICT systems will give rise to new demand for home and community care service, by improving prevention programs, as well as diagnoses and treatments of diseases. This would reflect into a higher utilization rate of services despite possible rebound effects and direct cost reductions related to the use of new technologies.

Most recent eHealthcare plans aim at pursuing equity as it reduces disparities in healthcare treatments between social groups. Equity in the healthcare sector may be defined as the act of eliminating unfairness between different population groups, by providing healthcare regardless of prevailing social attributes or capacity to pay. Improvements in health equity can easily lead to improvements in population health status as everyone gains access to healthcare and assistance services needed.

Nevertheless, even where universal access to healthcare services is in place, as it actually is in most well developed countries including Italy, there may still be a range of barriers that impede the utilization of healthcare services. Examples of inequalities within the Italian National healthcarecare System are those particularly marked by organizational factors such as waiting lists, availability of medical services $24 / 7$, lack of information (patient's clinical history files), as well as the physical distance of hospital facilities from citizens. One of the core objectives pursued by the Italian Healthcare System is to reduce inequalities in care, which we have seen to be mostly associated with education level, and to improve access to services for lower socio-economic groups, leading to differences in mortality rates.

External assessments are related to the perception that citizens have of healthcare services they receive. A typical method used for the collection of information is represented by personal interviews, as well as electronic and telephone surveys. Public institution that search for reliable data to undertake reasoned organizational and strategic assessment processes, need to struggle to produce highly articulated questionnaire that include all central and marginal aspects of the healthcare services offered to citizens, as users' perspective of the service is easily distorted by a variety of variables.

Internal assessments are made by requesting medical employees to fill in questionnaires that measure their degree of satisfaction to healthcare practices. Providers that aim to improve health outcome must rely on IT systems to better support change of healthcare practices and procedures, while increasing the degree of awareness in staff in compliance with the objectives and goals sought.

It is important to specify that internal evaluation results are also subjected to data distortion threats, since it is relatively difficult for humans to produce completely objective assessments. Furthermore, these evaluation results are influenced, either consciously or unconsciously, by factors such as employee's role in the organization, 
the degree of access to medical care information, and training practices.

These measurements enable organizations to observe how resources are used, not only among local hospitals and clinics, but also within other medical sectors such as pharmacies, and primary care operators. Budget analysis helps providers understand if resources are efficiently allocated within the system, or if there are inefficiencies reported that may lead to unnecessary expenditures. The information that is analyzed includes data on the administration of local pharmacies, such as local pharmaceutical expenditure rates per-capita, which is useful for measuring if the consumption of certain major drugs can have an impact over expenditure in healthcare.

These high expenditures may influence providers' future decisions on how to invest and setup new competitive objectives. Most healthcare systems feature large fixed costs due to equipment, specialized and qualified personnel, as well as for structural requirements. It is believed that large savings may be obtained if those fixed costs are to be lowered by controlling the supply of hospital services through facility reconfiguration.

\section{Data Flow and Network Architectures}

The answer to major EU eHealth objectives is an increase in collaboration among social care organization and healthcare systems, through which an integration of systems can be reached, for efficient communication and information processing. The interoperability among these systems can only be fully achieved if different professionals in the healthcare field are willing to actively cooperate with each other, emphasizing what are the relevant contents for them to store in patients' files (Pagliari 2007; AbuKhousa, Mohamed, \& Al-Jaroodi, 2012; Zhang et al., 2017).

The integration processes have had the effect of increasing shareholders' equity, while keeping investments and time unchanged. In addition, health equity objectives can take precedence over short-term efficiency goals, as the provision of broader health coverage implies equal healthcare for the weaker social groups and for citizens living in isolated areas, services that are normally expensive for healthcare facilities.

New technologies are initially developed to fulfill certain needs, like improvements in efficiency, or to create new markets. Whatever the purpose might be, the intent of managers is to invest resources and money for the development of specific technologies that can emerge as dominant designs for competitors, within a given period of time. The reason for wanting to converge towards a single model rather than promoting competition between technological products lies in the increasing returns associated with the greater use of a certain technology, as well as in reductions in the cost of IT by virtue of economies of scale. In fact, for markets bound to network externalities, benefits that arise from the use of products tend to increase proportionally to the number of users of that same product. The benefits tend to increase as the number of users increases (network externalities), especially if compatibility is an important element and if interactions and communications with standardised languages are required. The modularity of IT applications makes it easier to customize environments according to user needs.

Such integrated systems enable hospital institutions to store large amounts of data for use for therapeutic purposes, evaluations and as support systems for proper decision making. Through the use of EHR, healthcare providers can better monitor the patient's health status, undertake better evaluation processes, identify issues within specific healthcare sectors, avoid redundant services, ascertain the existence of unnecessary resources or, conversely, ascertain the lack of resources needed for particular treatments. In general, they allow end users to access the healthcare system more efficiently. While further benefits relate to medical error reductions, avoiding redundancy of diagnostic tests, reductions in hospitalization rates as a consequence of reduced length of hospital stay, as well as gaining a more efficient prescribing systems for a better control of drug use and expenditure.

Even larger savings are generating through a comprehensive interoperable information system, as having more and more medical departments gain access to patients' health information sooner contributes to save human lives, especially within emergency and ICUs. The storage of large amounts of patient's data within databases is essential to answer to questions such as "are we giving users the service they are searching for?", besides allowing providers to argue over the appropriateness of their strategies, and open up to different solutions that may better fit citizens' health need (Bezin et al., 2017; Guo et al., 2016).

However, the lack of legislation in Italy and the absence of a national and international entity empowered to coordinate the development of dominant standards, not just limited to the healthcare sector, along with the known complexity of large information systems, often leads to the propagation of stand-alone systems that are not capable of communicating with each other, nor be ordained for automated decision support systems. Despite greater investments and expenditures, the main issue to these individual innovations is related to the development of fragmented information systems that generate erroneous or incomplete data leading to increased 
medical errors.

The Tuscan Region is currently cooperating with the Laboratory Management and Health of Scuola Superiore Sant'Anna of Pisa to define healthcare IT strategies (Nuti, 2010; Nuti, 2008) that can lead to integrated solutions at a local level, with the scope to increase equity and access to care, reduce costs of services, increase the efficiency of resource utilization, and improve the overall quality healthcare. Regional policymakers truly believe that integration is the key element to success for completely efficient healthcare IT systems. In fact, they affirm that to exploit the full potential of electronic medical systems, it is necessary to integrate IT products with patients' medical information that is produced from local and national healthcare departments, along with electronic patient notes, e-prescriptions, laboratory and radiology results, or any other existing electronic patients' documentation produced, which contributes to maximize health performance results. The idea that relies behind interoperability of healthcare IT systems is that researchers that gain access to extensive data that computerized and IS collects and stores from patient's clinical records can easily provide support and evidence-based guidelines by comparing effectiveness of treatments for different care pathways.

To this regard, the epSOS project (Moharra et al., 2015) was established to supports eHealthcare strategies with the intent to build interoperable communication service infrastructure between healthcare systems in Europe. Granting quick access to patient's medical data by cross-border healthcare systems, which is made possible through the adoption of ICT infrastructures, is believed to improve the quality and safety of health by reducing the frequency of medical errors. In fact, access to patient's summery information in emergency situations, beside reducing the risk of medical errors, it also speeds up treatment process and reduces the repetition of diagnostic tests recently taken by users.

The availability of patients' medical data facilitates the provision of healthcare services even outside hospitals and treatment centres, with a resulting general improvement in treatment. Furthermore, users may perceive greater benefits from decentralized models as local authorities have greater opportunities to establish personal and more confidential relationships with patients (Tomar et al., 2019).

By considering the crucial role that Regions play in the Italian healthcare system, and how this fosters the creation of separate multidimensional IT systems, each of the which respondent to particular local needs, flexibility becomes an important factor for a successful integration process. In fact, flexibility allows maximizing the efficiency of use by avoiding useless duplications of products, infrastructures, systems, programs, and even of clinical data. Therefore, an efficient cooperation among professionals may be facilitated by the adoption of open standards, allowing each region to implement an individual system that may better fit single local health needs from one side, and gain the typical benefits of centralized systems from the other, to reduce avoidable expenses in terms of data collection, validation and maintenance of a huge amount of clinical information, as well as providing interoperable software which can irradiate among healthcare stakeholders either at a national or international level. The goal is to create a nation-wide database accessible by all regions of Italy, containing all the information determined by doctor-patient interactions, but not only limited to, needed to monitor health performance of the system as a whole.

Healthcare IT applications rely on few basic requirements needed for their implementation. First of all, a main telephone line is required, over which data or SMS alerts can be transmitted with the aim of reaching doctors within the infrastructure. Then you need a software application capable of acquiring, processing, storing and transmitting real-time patient information, digitally collected from devices and sensors. The software application permits the standardization of protocols for wireless communication, both inside and outside hospital facilities. At last, the use of sensor devices to be worn by patients in order to gather, process, store and transmit users' physiological health values.

The costs (Agha, 2014) consist of initial expenses (e.g. hardware and software components), expenditures for the implementation of the system, while additional periodic costs are due to licensing and system maintenance. From a financial point of view, the opportunity cost due to the lack of investment alternatives and the time needed (cost) due to the training of technicians, doctors and specialists must of course as well be considered.

Being able to access patients' summery files helps hospitals reduce costs, as it prevents physicians or specialists from duplicating diagnostic examinations that may have been taken recently from patients. Moreover, it allows healthcare providers access patients' medical charts from different healthcare departments in real time, enabling automatic transmission of urgent clinical information throughout the healthcare network at a national level, for diagnostic results or medical treatment practices ordered from physicians and GPs, or for sending digitalized images originated from radiological units through the use of RIS/PACS applications (Boochever, 2004). In addition, it allows patients to be adequately seen by specialist, and transmit results and referrals immediately to 
GPs for adequate therapy dispositions.

Savings derived from the use of HER are not just related to the cost of paper, or to the time saved by medical staff from filing and searching for folders, but covers the cost of large storage places required for the preservation of hard copies of patients' clinical charts over time. Further benefits arising from the use of computerized information applications in hospital facilities, regard the alert feature that allows different healthcare departments to cheaply access new guidelines and procedures, as well as providing feedbacks to doctors and medical specialists over the quality of the service they deliver, which can be benchmarked with national and international performance indicators to measure the degree of competitiveness of the internal system.

\section{IT Benefits to Hospitals and Local Healthcare Centers: The Case of Italy}

Healthcare service is currently delivered in Italy mainly by publicly funded hospital structures. Besides the wide number of hospitals, there are many ASL centers displaced throughout the territory, generally identified as facilities providing support to hospitals, and helping them to unburden from low-relief medical services. Private clinics and ambulatory centers are distinguished from public hospitals as they are for-profit structures funded by the private sector mainly for the treatment of outpatients.

All hospitals have an emergency care unit which is dedicated to first aid interventions. Emergency care units constitutes the main access point to hospital facilities and medical treatments for patients suffering from acute conditions, whether they reach the facility by ambulance service or by their own means. Some admitted patients may be immediately dismissed after treatment, these are known as outpatients, while other patients stay for special diagnostic tests, or for receiving further healthcare treatments for an undetermined period of time, depending on the gravity of the disease. All patients entering an emergency care department in Italy are subjected to triage, that is a system used for the determination of priorities to be assigned according to increasing urgency codes that depend on the severity of patients' clinical status, and not on the simple arrival order.

Most critical conditions managed in emergency departments concern patients reporting cases of cardiac arrest, myocardial infractions, physical trauma, chronic respiratory diseases and chronic obstructive pulmonary disease (COPD), all of the which require timely treatments. One common problem to many emergency units across European countries is represented by the inability to manage overcrowding situations. A healthcare facility that is not able to manage the abundant flow of urgent requests, due to the insufficient presence of qualified personnel, or because of long handling times, results in poor quality treatments and inadequate healthcare services.

Future eHealthcare strategies are believed to have an impact on national healthcare expenditure, as most Regional healthcare plans are undergoing assessments of IT implementations within hospitals and local healthcare centers. It is well known that IT/IS deployment require significant efforts and entail large expenditures, especially when the objective is to setup an integrated system among healthcare stakeholders. For this reason, it is estimated that healthcare expenditure in Italy may notably increase within the next years.

Increments in public expenditure provide evidence of the efforts made by governments to improve healthcare by investing in R\&D activities for the development of new technologies, to deliver a more qualitative and equitable healthcare system, despite the context of economic restrain that has been characterizing the Italian market in recent years. Nevertheless, public enterprises are bound to operate to ensure top quality services at the lowest cost possible, not because of profit objectives, but rather to secure continuity in the delivery of healthcare services as well as improvements over time. Keeping this in mind, it is reasonable to comprehend that social costs may influence utilization of new technologies from public care structures, as they may be worried about the impact that such innovations may have on expenditure.

Despite all the efforts made, there are still inefficiencies reported in Italy particularly between northern and southern regions of the country in the allocation of healthcare resources, as well as in the application of common standard qualitative medical practices, bearing citizens to a sanitary migration phenomenon.

In fact, there are several cases of medical malpractice within some Italian hospitals, particularly in southern regions of the country, pointing out disparities and inequalities of treatments. According to a 2007 Svimez report (Petraglia and Scalera 2012), each year 197,000 southern resident citizens on average migrate to central or northern regions of Italy to undergo diagnostic procedures or therapies, whereas only 49,000 northern resident citizens make the reverse trip. To this regard, the adoption of integrated IT systems can sharply contribute to address the criticalities pointed out from domestic medical migration of resident citizens from southern to northern regions of the country, safeguarding southern hospital structures from avoidable medical errors.

It is true that IT increases healthcare costs at first (Fleming et al. 2011), but in the long run it leads institutions to 
a number of benefits, by improving the quality of therapies and treatments, increasing access to care, reducing processing time and eliminating wastes and inefficiencies. In addition, digitalized applications and services that are adopted from an increasing number of physician offices and hospitals, are expected to have an effect on prices, as the growth in the demand of IT applications is expected to reduce unitary costs. Without mentioning that prices of such healthcare IT products appear to be falling, as the use of internet-based applications and information management systems are becoming more and more available, and tend to respond to common standardized communication protocols and requirements set by international eHealth strategy plans.

Telehealth is believed to improve healthcare practice by the provision of innovative cost-effective products, and by delivering qualitative healthcare treatments to a greater number of individuals, particularly in rural areas of the world where healthcare is mostly needed (Dallery, Kurti, \& Erb, 2015; Brosnan \& Hickey, 2016). Public hospitals as well as private clinics have recently been increasing their interest in tele-consultations, as it enables personnel to gain access to precious medical information, allowing timely communication of new medical guidelines or receiving simple updates from policy makers, leading to savings in time and expenditure as a result of e-training courses.

Telehealth can be extremely useful for various healthcare departments such as cardiology units for the transmission of ECG tracing, radiology units for the digitalization of x-ray images, dermatology departments for the creation of digitalized cutaneous abrasion images, and even by gynecologists which can benefit from the monitoring of patient's health status during pregnancy.

The application of Telehealth opens up markets and favors the initiation of new healthcare products and service to effectively meet patient health needs. In fact, it enables healthcare systems to improve diagnosis procedures as it allows medical information to be easily transferred to professionals, for example for tele-refertation purposes (Schwamm et al. 2017), anytime and regardless of where they are located. In addition, it promotes dynamic interoperability operations among medical staff, and tele-learning by linking doctors together. Telehealth is also believed to improve quality of care, as the creation of a digitalized healthcare network makes it possible for medical staff to timely consult information about the availability of beds within a particular unit or department, providing real time access to booking lists, and helping hospitals reduce waiting time (Ginter, Duncan, \& Swayne, 2018).

The increasing experiences gained by some local healthcare providers raise awareness over the relevance of ICT in meeting quality and efficiency objectives through cost-effective solutions. In fact, the use of ICT is seen as an enabling technology, leading to improvements in the access to health information through EHR systems, monitoring of major health threats, increased cooperation and dissemination of medical best practices, as well as the automation of certain administrative processes.

However, the Italian scenario is still characterized for having developed isolated, random, and uneven excellence of ICT applications throughout the national territory. Many of the difficulties of IT adoption revealed are often identified at a political or organizational level. Apart from the lack of skilled resources, most barriers to the development of innovation are attributed to the persistent inability of experts to set effective network-based approaches. A 2004 OECD study measuring the level of use of ICT tools to improve the efficiency of business processes has showed a relatively low adoption rate across most EU countries. For this reason, the Italian Ministry of Health is working for the promotion of healthcare IT applications, and to this regard it established a partnership with the Emilia Romagna Region for the creation of a National Observatory for assessments and monitoring of eCare applications, to carry out analytical examination of home-care services and disclose standardized best practices of Telehealth throughout the territory. As of today there are many Regions participating in the Observatory project such as Tuscany, Liguria, Marche, Campania, Veneto, Sicily and at last, the Lombardy Region which joined in 2011.

The refinement of technology throughout time has helped healthcare organizations increase their efficiency from one hand, and open up to new cost-effective treatment practices and therapies in the other. For example, monitoring systems are useful for hospitals, clinics and local authorities, not only for information collection purposes, but also because it enables them to overlook to the health status of patients undergoing treatments for a wide range of vital medical parameters such as blood pressure, oxygen saturation, heart rate, respiration rate, electroencephalography (EEG) and electrocardiography (ECG). It is no surprise that such systems result particularly useful to emergency care units, as well as different specialized care departments such as neonatal units, cardiovascular units, and respiratory departments, where admitted patients are generally affected by acute disease that require timely therapies and interventions.

One of the major liabilities in healthcare is related to privacy of patients' data. It is estimated that approximately 
150 employees regularly consult parts of a patient's medical record during their stay, while at least 600.000 individuals among providers, researchers, and other third party subjects gain access to portions of patients' reserved data for treatment purposes, statistical analysis, prevention program definitions, and other administrative needs. Considering that a completely interoperable national IT system is believed to be accessed by almost 12 million individuals, precisely 16 times as much the number of people that regularly access ordinary paper charts, it is easy to comprehend that the transition to a computerized care system may require greater efforts in terms of security and data protection plans. The objective would be to avoid that a pharmacist in Rome may gain access to a laboratory examination result of his daughters' fiancé living in Milan, just to make sure he is not a drug attic or has an alcoholic habit.

The great number of information that healthcare providers acquire from IT adoption empowers hospital institutions to set adequate strategies for the development of appropriate prevention programs. Correct prevention programs help reduce demand for care for acute diseases, and consequently lowers hospitalization of inpatients, leading to reduced medical expenditures. Furthermore, hospitals can rely on precious information to reduce frequent and costly medical errors, for example due to allergic drug reactions that can lead to lags in discharges, and consequently increase the length of stay of inpatients.

In addition, latest technologies enable hospitals the provision of medical practice to patients remotely, that is patients receiving healthcare treatments while staying home instead of requiring users to travel to hospital structures, leading to the delivery of new cost-effective care solutions that increase perceived quality of service. As an example, the Freeman hospital gained conspicuous savings from the introduction of a relatively cheap technological device called CardioQ (Bour, 2018). The clinical trials carried to a limited number of patients showed that CardioQ users had notable benefits compared to patients receiving standard treatment practice. In fact, CardioQ patients were ready for discharge 3 days' sooner, tolerated food 2 days earlier, were less affected from post-operative difficulties (only 2 percent of the patients reported complications rather than 15 percent), and most importantly, none of the patients required unexpected admission to ICUs, whereas 11 percent of ordinary patients necessitated critical care treatment.

The storage of patients' medical information in electronic databases can be also very useful for hospitals and local healthcare centers to reduce medical errors, as it prevents physicians from administering erroneous medications or therapies to users. Computerized Providers Order Entry (CPOE), enables the sharing of large amounts of data to be accessed by different providers, speeding up treatment processes, and at the same time enhancing medical services to better fit individual requirements. Clearly, lowering the number of malpractice generates different positive returns, not only in terms of quality, or of users' perceived service, but also in terms of reduced healthcare expenditure as demonstrated by the Freeman Hospital case (Breen et al., 2019).

A research conducted by the RAND Healthcare IT Project team (Blumenthal 2009), reported that hospitals and local authorities could save remarkable amount of money if they were to install CPOE applications. Analysis suggested that U.S. hospitals that introduced CPOE prevented 200.000 adverse drug incidents, and saved over $€$ 800 million each year.

EHRs or similar informatics systems (Blobel, 2006; Payne et al., 2015) require hospitals to rely on technicians to validate patient health information that is entered by medical staff. In fact, technicians are responsible for the validation of data, ensuring that all requested portions of patients electronic records are complete and signed by appropriate medical staff, as well as granting round-the-clock access to all stakeholders of the healthcare system.

Aside from technicians, the expansion of healthcare IT software within medical facilities such as hospitals, ASL centers, ambulatory units, laboratories, radiology departments, pharmacies, as well as within other private and public medical organizations, foster markets to a proactive approach to establishing new competences and knowledge development, and consequently lead to the formation of new professionally qualified roles.

There is evidence of different technological developments that address traceability, identification and management issues of information that is acquired by healthcare centers. The hospital Spedali Civili of Brescia in collaboration with the RFId Solution Center of the Polytechnic di Milano, has undertaken a research project to improve quality and efficiency of care practice through the use of Radio Frequency Identification (RFId) tags, enabling hospitals to trace and identify medical pathways, for example with regards to blood donation and blood transfusion services which are subjected to proper testing, and to meet safety and reliability guidelines.

Such technologies are found to be valuable solutions helping hospitals keep track of resources and packages paths while navigating through the healthcare system. When applied to blood donations, RFId technologies ensure greater protection and safety of the donor, as well as of patients receiving transfusion. The traceability is made possible due to the application of a bar code labeling on blood bags, which allow hospitals to uniquely 
identify packages, and access information related to the donor, the bag, as well as the receiver of the transfusion in real time. It is believed to be extremely important to be able to timely identify and access information on the history and paths of blood bags to avoid medical errors or transfusion risks.

In addition to reductions in medical errors and improvements in the quality of medical treatments, RFId technologies can help hospital organizations improve their efficiency though the automation of certain repetitive and low-relief activities, thus simplifying the work of medical operators and freeing a significant share of man hours, particularly from qualified profiles which represents a great cost-containment opportunity.

The social benefits that patients suffering from certain illnesses or pathologies experience from the identification of better healthcare pathways, is mainly related to the ability of hospitals and care providers to reduce the risk of clinical errors (quality benefits), while speeding up treatment processes (efficiency benefits), which at times may result lifesaving. As hospitals comply to patient-centric guidelines and customer care increases among healthcare organizations, patients have a better chance of perceiving a greater quality of treatment, which in turn reflects in a growth of customer satisfaction (external assessments). In the other hand, the optimization of employees work habits leads to improvements in procedures, and attributes increased motivation to medical staff in reaching and maintaining high professional standards, which in turn determines employee satisfaction (internal assessments).

\section{Conclusion and Implications for Policy Makers and Managers}

IT within healthcare is a relevant topic and a multidisciplinary one. While many efforts are being made in most developed countries, it is noteworthy that many others still struggle in implementing an effective eHealth system. Besides designing a comprehensive IT system for healthcare, it is very important to develop sets of KPI and metrics to measure the actual improvements and overall efficiency of the system itself.

In computer information science, interoperability is defined as "the ability to communicate, execute programs, or transfer data between different functional units in such a way that users' have little or no knowledge of the unique characteristics of such entities". Thus, IT within healthcare can be considered to be interoperable, if it can exchange appropriately and clearly a specific set of clinically relevant information.

Integration processes covers a number of vertical units such as cardiology departments, laboratories and radiology units, as well as some cross functional clinical practices needed for the coordination of patients' treatments, and of horizontal domain's for the correct implementation of IT infrastructures.

As said, healthcare in Italy is provided through the support of different individual interconnected entities. The multiple benefits arising from the adoption of IT systems are believed to affect all stakeholders involved in the delivery of medical treatments at a national level, including hospital facilities, local authorities, ASL centers, private clinics, laboratories, physicians, GPs, patients, other care providers, pharmaceutical companies, bio-technological industries, computer industries, and many others.

The increased availability of information that is obtained through the use of computerized applications facilitates the establishment of external collaborations and alliances with community vendors, healthcare authorities, fire fighters, police departments and other professionals involved in the delivery of primary care assistance, telecommunication companies leading to faster data exchange among partners, and contributing to improve the outcome of healthcare services. This can be especially significant for the management of crucial services such as telehealth and telecare, where users can benefit of continuous home monitoring of vital signs particularly by those affected by diabetes, COPD or suffering from heart failure.

Establishing a common communication channel, as well as making data accessible to all providers, promotes the dissemination of visions, shared protocols, guidelines and the standardization of certain treatment pathways, which lead to further simplification of relationships and stronger partnerships among healthcare stakeholders.

Healthcare organizations rely on different technological interoperable systems, allowing remote monitoring of patient's health status in real time, and the detection of pathological values in advance. This helps hospitals and ASL centers to set adequate and efficient prevention strategies to reduce deaths caused by various illness.

Despite the number of benefits listed, the adoption of digitalized and telematics products is not cost free. As we have seen, new technological products besides having a rebound effect, they tend to increase the demand for services, affect markets and create new job and qualified mansions within the healthcare sector.

Nevertheless, IT investments in hardware and software doesn't necessarily have to be costly. Sometimes, in-house analytic capabilities using existing software licenses are all that is necessary to enable the healthcare systems to generate the required insight.

Healthcare providers typically receive and store data from hospitals, clinicians, and pharmacies in separate 
databases. To make the information more useful, they should simply be linked and integrated with a patient identifier number in order to determine what medications, treatments, and other medical interventions users received. Discovering that some patients are being over-treated or undertreated, while others are being treated the wrong way can help find specific ways to improve patient care and better control expenses.

Individuals who are frequently asked to travel, whether for business or for personal matters, experience fragmented care which worsens patient's health status. The adoption of integrated and interoperable digitalized application, as well as the wider use of telemedicine products, ensures patients continuity of care, preventing the onset of complications or of deterioration in population health levels.

The use of integrated IS allows healthcare providers to make appropriate evaluations over current healthcare strategies, and verify the suitability of guidelines and procedures. In addition, it allows providers to detect and eliminate inefficiencies reviled in the current system, such as the duplication of diagnostic examinations, and reduces medical errors, which is expected to lower as providers acquire greater information on patient's health status. In fact, medical errors are responsible for increasing healthcare expenditure as hospital are found to readmit discharge patients for costly emergency unit treatments and therapies.

The success of healthcare strategies depends in part on the automation of certain healthcare procedures such as the administrative and discharge practices, while on the other hand it relies on the capabilities that health administrators have to define population needs. Further benefits are given by the automation of certain practices such as the transfer of referrals, medical data, and prescriptions among physicians and pharmacies, hospitals and laboratory referrals, radiologists referrals, as well as the rationalization of resources, particularly of professional figures, greatly contributing to lowering public healthcare expenditures.

It is doubtless that the magnitude of the positive effects that healthcare IT systems generate affect the distribution and quickness of adoption of innovation technology equipment across the healthcare sector. As stakeholders perceive that benefits from the use of such systems are not only attributed to hospitals or local healthcare enterprises, but to the entire healthcare supply chain and to patients, there are greater incentives deriving from the wider spread of technologies alike, which lead to higher internal and external satisfaction levels.

The use of technologically advanced computer applications leading to improvements in health outcomes require radical transformation of previous work processes and procedures. Nevertheless, doctors are known to have an adverse behavior to change, and are reluctant to take advice on how to potentially improve their work flow or healthcare practices especially if suggested from non-medical personnel.

Government leaders, healthcare institutions and policy makers assert how important it is to involve medical personnel in evaluation processes, to assure that innovation is adequately fit to meet the populations' health needs. If it is demonstrated that a particular treatment can be provided to a patient more effectively through the use of Healthcare IT applications, thus creating new best care practices, there wouldn't be any difficulty in having doctors accept change, increasing chances of success.

Healthcare policy makers are aware of the gap that Europe has in the application of IT, and therefore, has agreed to set common eHealthcare strategies to foster gap reduction within EU countries by promoting ICT-based systems. EU countries have arranged to share their experiences in healthcare managements and innovation technologies for the definition of best practices which may help stimulate the growth of a new promising industrial sectors, and improve quality of care within the area.

European eHealth Action Plans set objectives for the creation of interoperable IT systems. These objectives are remarked in almost all national healthcare strategies within the EU, but seldom they are properly defined as few countries have fully been able to developed a complete electronic healthcare information management system.

The potential of eHealth to improve health outcomes, already recognized by the World Health Assembly in 2005, has aroused attraction and high expectations from many healthcare stakeholders. Yet, EU countries interested in the deployment of healthcare IT systems have carried out so far only partial eHealth program lines such as patient summary or basic electronic patient records. These systems allow the storage of extensive patients' medical information, not only confined to local organizational boundaries, but extended to regional or even national levels.

Besides eHealthcare strategies, there are many other projects that have been undertaken by various EU countries to promote acquisition of technological expertise for healthcare purposes such as those announced by the epSOS project, an ICT policy support plan with the scope to exploit existing solutions to create interoperable cross-border communication systems. Further details of this will be provided in chapter four while examining network related benefits, and the existence of interoperable and integrated systems. 
The promotion of eHealth and epSOS projects have gained significant political support as of December 2009, when the European Council of Ministers, which is responsible for eHealth implementations, emphasized the importance of eHealth in the achievement of qualitative medical practices. Since then, many European governments have been persistently pushing for the digitalization of services and the adoption of IT applications, despite the awareness of known threats which may be inherent to countries' legislations, and related to security and privacy data protection, as well as to the definition of common standardized protocols for the establishment of interoperability among different providers. This is a consequence of the many different individual approaches and structural configurations that each participating country developed for the delivery of healthcare practice. The challenge is to establish efficiencies through the deployment of shared information systems, to ensure interoperability between local, regional and national healthcare systems, without having to radically redesign or overturn current systems' settings of each individual participating country.

\section{References}

AbuKhousa, E., Mohamed, N., \& Al-Jaroodi, J. (2012). e-Health cloud: Opportunities and challenges. Future Internet, 4(3), 621-645. https://doi.org/10.3390/fi4030621

Agha, L. (2014). The effects of health information technology on the costs and quality of medical care. Journal of Health Economics, 34, 19-30. https://doi.org/10.1016/j.jhealeco.2013.12.005

Ahlholm, P., Lappalainen, R., Lappalainen, J., Tarvonen, P.-L., \& Sipilä, K. (2019). Challenges of the Direct Filling Technique, Adoption of CAD/CAM Techniques, and Attitudes Toward 3D Printing for Restorative Treatments Among Finnish Dentists. The International Journal of Prosthodontics, 32(5), 402-410. https://doi.org/10.11607/ijp.6343

Akter, S., Wamba, S. F., Gunasekaran, A., Dubey, R., \& Childe, S. J. (2016). How to improve firm performance using big data analytics capability and business strategy alignment? International Journal of Production Economics, 182, 113-131. https://doi.org/10.1016/j.jpe.2016.08.018

Baumol, W. J. (1986). Contestable markets: An uprising in the theory of industry structure. Microtheory: Applications and Origins, 40-54.

Ben-Assuli, O. (2015). Electronic health records, adoption, quality of care, legal and privacy issues and their implementation in emergency departments. Health Policy, 119(3), 287-297.https://doi.org/10.1016/j.healthpol.2014.11.014

Bezin, J., Duong, M., Lassalle, R., Droz, C., Pariente, A., Blin, P., \& Moore, N. (2017). The national healthcarecare system claims databases in France, SNIIRAM and EGB: Powerful tools for pharmacoepidemiology. Pharmacoepidemiology and drug safety, 26(8), 954-962. https://doi.org/10.1002/pds.4233

Birkinshaw, J., Zimmermann, A., \& Raisch, S. (2016). How do firms adapt to discontinuous change? Bridging the dynamic capabilities and ambidexterity perspectives. California Management Review, 58(4), 36-58. https://doi.org/10.1525/cmr.2016.58.4.36

Blobel, B. (2006). Advanced and secure architectural EHR approaches. International Journal of Medical informatics, 75(3-4), 185-190. https://doi.org/10.1016/j.ijmedinf.2005.07.017

Blumenthal, D. (2009). Stimulating the adoption of health information technology. New England Journal of Medicine, 360(15), 1477-1479. https://doi.org/10.1056/NEJMp0901592

Boella, G., \& Remondino, M. (2010). Collaboration and human factor as drivers for reputation system effectiveness. Lecture Notes in Business Information Processing, 45, 3-16. https://doi.org/10.1007/978-3-642-12436-5_1

Boochever, S. S. (2004). HIS/RIS/PACS integration: Getting to the gold standard. Radiol Manage, 26(3), 16-24.

Börsch-Supan, A., Brandt, M., Hunkler, C., Kneip, T., Korbmacher, J., Malter, F., \& Zuber, S. (2013). Data resource profile: The Survey of Health, Ageing and Retirement in Europe (SHARE). International Journal of Epidemiology, 42(4), 992-1001. https://doi.org/10.1093/ije/dyt088

Bour, J. J. (2018). Latest Advances in Cardiac Output Monitoring from High-Definition Impedance Cardiography. Current Anesthesiology Reports, 8(2), 238-244. https://doi.org/10.1007/s40140-018-0271-8

Breen, C., Maguire, K., Bansal, A., Russin, S., West, S., Dayal, A., \& Hohmuth, B. (2019). Reducing Phlebotomy Utilization with Education and Changes to Computerized Provider Order Entry. The Journal for Healthcare Quality (JHQ), 41(3), 154-159. https://doi.org/10.1097/JHQ.0000000000000150 
Broadbent, M., Weill, P., \& St. Clair, D. (1999). The implications of information technology infrastructure for business process redesign. MIS Quarterly, 159-182. https://doi.org/10.2307/249750

Brosnan, C. A., \& Hickey, J. V. (2016). Future Trends and Challenges in Evaluation. Evaluation of Healthcare Quality for DNPs. https://doi.org/10.1891/9780826131584.0014

Bryson, J. M. (2018). Strategic planning for public and nonprofit organizations: A guide to strengthening and sustaining organizational achievement. John Wiley \& Sons.

Carayannis, E. G., Meissner, D., \& Edelkina, A. (2017). Targeted innovation policy and practice intelligence (TIP2E): Concepts and implications for theory, policy and practice. The Journal of Technology Transfer, 42(3), 460-484. https://doi.org/10.1007/s10961-015-9433-8

Chen, H.-M., Kazman, R., Garbajosa, J., \& Gonzalez, E. (2016). Toward big data value engineering for innovation. Proceedings of the 2nd International Workshop on BIG Data Software Engineering, 44-50. ACM. https://doi.org/10.1145/2896825.2896837

Cruz-Jesus, F., Oliveira, T., \& Bacao, F. (2012). Digital divide across the European Union. Information \& Management, 49(6), 278-291. https://doi.org/10.1016/j.im.2012.09.003

Dallery, J., Kurti, A., \& Erb, P. (2015). A new frontier: Integrating behavioral and digital technology to promote health behavior. The Behavior Analyst, 38(1), 19-49. https://doi.org/10.1007/s40614-014-0017-y

De Gagne, J. C., Bisanar, W. A., Makowski, J. T., \& Neumann, J. L. (2012). Integrating informatics into the BSN curriculum: A review of the literature. Nurse Education Today, 32(6), 675-682. https://doi.org/10.1016/j.nedt.2011.09.003

De Vries, H., Bekkers, V., \& Tummers, L. (2016). Innovation in the public sector: A systematic review and future research agenda. Public Administration, 94(1), 146-166. https://doi.org/10.1111/padm.12209

Fenger, H. M. (2007). Welfare regimes in Central and Eastern Europe: Incorporating post-communist countries in a welfare regime typology. Contemporary Issues and Ideas in Social Sciences, 3(2).

Ferlie, E., Fitzgerald, L., \& Pettigrew, A. (1996). The new public management in action. USA: Oxford University Press. https://doi.org/10.1093/acprof:oso/9780198289029.001.0001

Ferré, F., de Belvis, A. G., Valerio, L., Longhi, S., Lazzari, A., Fattore, G., \& Maresso, A. (2014). Italy: Health system review.

Fleming, N. S., Culler, S. D., McCorkle, R., Becker, E. R., \& Ballard, D. J. (2011). The financial and nonfinancial costs of implementing electronic health records in primary care practices. Health Affairs, 30(3), 481-489. https://doi.org/10.1377/hlthaff.2010.0768

Fuller, C. W. (1997). Key performance indicators for benchmarking health and safety management in intra-and inter-company comparisons. Benchmarking for Quality Management \& Technology, 4(3), 165-174. https://doi.org/10.1108/14635779710181406

Garrido, T., Jamieson, L., Zhou, Y., Wiesenthal, A., \& Liang, L. (2005). Effect of electronic health records in ambulatory care: Retrospective, serial, cross sectional study. Bmj, 330(7491), 581. https://doi.org/10.1136/bmj.330.7491.581

Ginter, P. M., Duncan, W. J., \& Swayne, L. E. (2018). The strategic management of healthcare organizations. John Wiley \& Sons.

Grol, R. P., Bosch, M. C., Hulscher, M. E., Eccles, M. P., \& Wensing, M. (2007). Planning and studying improvement in patient care: The use of theoretical perspectives. The Milbank Quarterly, 85(1), 93-138. https://doi.org/10.1111/j.1468-0009.2007.00478.x

Guo, C., Zhuang, R., Jie, Y., Ren, Y., Wu, T., \& Choo, K.-K. R. (2016). Fine-grained database field search using attribute-based encryption for e-healthcare clouds. Journal of Medical Systems, 40(11), 235. https://doi.org/10.1007/s10916-016-0588-0

Hillestad, R., Bigelow, J., Bower, A., Girosi, F., Meili, R., Scoville, R., \& Taylor, R. (2005). Can electronic medical record systems transform healthcare? Potential health benefits, savings, and costs. Health affairs, 24(5), 1103-1117. https://doi.org/10.1377/hlthaff.24.5.1103

Hripcsak, G., \& Albers, D. J. (2012). Next-generation phenotyping of electronic health records. Journal of the American Medical Informatics Association, 20(1), 117-121. https://doi.org/10.1136/amiajnl-2012-001145

Jensen, P. B., Jensen, L. J., \& Brunak, S. (2012). Mining electronic health records: Towards better research 
applications and clinical care. Nature Reviews Genetics, 13(6), 395. https://doi.org/10.1038/nrg3208

Kerzner, H. (2019). Using the project management maturity model: Strategic planning for project management. Wiley. https://doi.org/10.1002/9781119559078

Kim, S.-Y., \& Huynh, T.-A. (2008). Improving project management performance of large contractors using benchmarking approach. International Journal of Project Management, 26(7), 758-769. https://doi.org/10.1016/j.ijproman.2007.10.002

Laakkonen, A., Hujala, T., \& Pykäläinen, J. (2019). Integrating intangible resources enables creating new types of forest services-developing forest leasing value network in Finland. Forest Policy and Economics, 99, 157-168. https://doi.org/10.1016/j.forpol.2018.07.003

Lagu, T., Lindenauer, P. K., Rothberg, M. B., Nathanson, B. H., Pekow, P. S., Steingrub, J. S., \& Higgins, T. L. (2011). Development and validation of a model that uses enhanced administrative data to predict mortality in patients with sepsis. Critical Care Medicine, 39(11), 2425-2430. https://doi.org/10.1097/CCM.0b013e31822572e3

Leandri, S. J. (2001). Measures that matter: How to fine-tune your performance measures. The Journal for Quality and Participation, 24(1), 39.

Lemire, M., Paré, G., Sicotte, C., \& Harvey, C. (2008). Determinants of Internet use as a preferred source of information on personal health. International Journal of Medical Informatics, 77(11), 723-734. https://doi.org/10.1016/j.jimedinf.2008.03.002

Lu, Y. (2017). Industry 4.0: A survey on technologies, applications and open research issues. Journal of Industrial Information Integration, 6, 1-10. https://doi.org/10.1016/j.jii.2017.04.005

Lustria, M. L. A., Smith, S. A., \& Hinnant, C. C. (2011). Exploring digital divides: An examination of eHealth technology use in health information seeking, communication and personal health information management in the USA. Health Informatics Journal, 17(3), 224-243. https://doi.org/10.1177/1460458211414843

Moharra, M., Almazán, C., Decool, M., Nilsson, A.-L., Allegretti, N., \& Seven, M. (2015). Implementation of a cross-border health service: Physician and pharmacists' opinions from the epSOS project. Family Practice, 32(5), 564-567. https://doi.org/10.1093/fampra/cmv052

Namachivayam, P., Shann, F., Shekerdemian, L., Taylor, A., van Sloten, I., Delzoppo, C., \& Butt, W. (2010). Three decades of pediatric intensive care: Who was admitted, what happened in intensive care, and what happened afterward. Pediatric Critical Care Medicine, 11(5), 549-555. https://doi.org/10.1097/PCC.0b013e3181ce7427

Noe, R. A., Hollenbeck, J. R., Gerhart, B., \& Wright, P. M. (2017). Human resource management: Gaining a competitive advantage. McGraw-Hill Education New York, NY.

Nuti, S. (2010). Il sistema di valutazione della performance della sanità toscana—Report 2009. Edizioni ETS. ISBN, 616259875.

Nuti, Sabina. (2008). Il sistema di valutazione della performance in sanità. Bologna: Il Mulino.

Organization, W. H. (2006). Working together for health: The World health report 2006: policy briefs.

Pagliari, C. (2007). Design and evaluation in eHealth: Challenges and implications for an interdisciplinary field. Journal of medical Internet research, 9(2), e15. https://doi.org/10.2196/jmir.9.2.e15

Payne, T. H., Corley, S., Cullen, T. A., Gandhi, T. K., Harrington, L., Kuperman, G. J., ... Tang, P. C. (2015). Report of the AMIA EHR-2020 Task Force on the status and future direction of EHRs. Journal of the American Medical Informatics Association, 22(5), 1102-1110. https://doi.org/10.1093/jamia/ocv066

Petraglia, C., \& Scalera, D. (2012). Le politiche per il Mezzogiorno negli anni della crisi (2007-2012). Rivista economica del Mezzogiorno, 26(4), 1023-1048.

Rabin, R., \& Charro, F. de. (2001). EQ-SD: A measure of health status from the EuroQol Group. Annals of Medicine, 33(5), 337-343. https://doi.org/10.3109/07853890109002087

Remondino, M. (2005). Reactive and deliberative agents applied to simulation of socio-economical and biological systems. International Journal of Simulation: Systems, Science and Technology, 6(12-13), 11-25.

Remondino, M., \& Boella, G. (2010). How users' participation affects reputation management systems: The case of P2P networks. Simulation Modelling Practice and Theory, 18(10), 1493-1505. https://doi.org/10.1016/j.simpat.2010.05.010 
Remondino, Marco. (2018). Information Technology in Healthcare: HHC-MOTES, a Novel Set of Metrics to Analyse IT Sustainability in Different Areas. Sustainability, 10(8), 2721.

Renahy, E., Parizot, I., \& Chauvin, P. (2008). Health information seeking on the Internet: A double divide? Results from a representative survey in the Paris metropolitan area, France, 2005-2006. BMC Public Health, 8(1), 69. https://doi.org/10.1186/1471-2458-8-69

Saltman, R. B., \& Figueras, J. (1998). Analyzing The Evidence On European Healthcare Reforms: Experience in western European healthcare systems suggests lessons for reform in the United States, according to a major international comparison by the World Healthcare organization. Health affairs, 17(2), 85-108. https://doi.org/10.1377/hlthaff.17.2.85

Schwamm, L. H., Chumbler, N., Brown, E., Fonarow, G. C., Berube, D., Nystrom, K., \& Radhakrishnan, K. (2017). Recommendations for the implementation of telehealth in cardiovascular and stroke care: A policy statement from the American Heart Association. Circulation, 135(7), e24-e44. https://doi.org/10.1161/CIR.0000000000000475

Sheng, X., \& Simpson, P. M. (2013). Seniors, health information, and the Internet: Motivation, ability, and Internet knowledge. Cyberpsychology, Behavior, and Social Networking, 16(10), 740-746. https://doi.org/10.1089/cyber.2012.0642

Shohet, I. M. (2006). Key performance indicators for strategic healthcare facilities maintenance. Journal of Construction Engineering and https://doi.org/10.1061/(ASCE)0733-9364(2006)132:4(345)

Short, J. E., \& Venkatraman, N. (1992). Beyond business process redesign: Redefining Baxter's business network. MIT Sloan Management Review, 34(1), 7.

Simonazzi, A. (2008). Care regimes and national employment models. Cambridge Journal of Economics, 33(2), 211-232. https://doi.org/10.1093/cje/ben043

Steiss, A. W. (2019). Strategic management for public and nonprofit organizations. Routledge.

Tidd, J., \& Bessant, J. R. (2018). Managing innovation: Integrating technological, market and organizational change. John Wiley \& Sons.

Tomar, D., Bhati, J. P., Tomar, P., \& Kaur, G. (2019). Migration of healthcare relational database to NoSQL cloud database for healthcare analytics and management. In Healthcare Data Analytics and Management (pp. 59-87). Elsevier. https://doi.org/10.1016/B978-0-12-815368-0.00002-6

Tony, O. A., Ashiru, O. B., Kehinde, J. O., \& Oluwatoyin, A. (2018). Imperatives of Information and Communication Technology On Potencies and Skill Gaps of Educators and Undergraduates of Higher Education Institutions in Nigeria. International Journal of Information, Business and Management, 10(1), 49-61.

Torchia, M., Calabrò, A., \& Morner, M. (2015). Public-private partnerships in the healthcare sector: A systematic review of the literature. Public Management Review, 17(2), 236-261. https://doi.org/10.1080/14719037.2013.792380

Turnock, B. (2012). Public health. Jones \& Bartlett Publishers.

Valverde, U., Nadeau, J.-P., \& Scaravetti, D. (2017). Finding Innovative Technical Solutions in Patents Through Improved Evolution Trends. In TRIZ-The Theory of Inventive Problem Solving (pp. 1-42). Springer. https://doi.org/10.1007/978-3-319-56593-4_1

Vicente, M. R., \& López, A. J. (2011). Assessing the regional digital divide across the European Union-27. Telecommunications Policy, 35(3), 220-237. https://doi.org/10.1016/j.telpol.2010.12.013

Vincent, J. L., \& Singer, M. (2010). Critical care: Advances and future perspectives. The Lancet, 376(9749), 1354-1361. https://doi.org/10.1016/S0140-6736(10)60575-2

Zhang, Y., Qiu, M., Tsai, C.-W., Hassan, M. M., \& Alamri, A. (2017). Health-CPS: Healthcare cyber-physical system assisted by cloud and big data. IEEE Systems Journal, 11(1), 88-95. https://doi.org/10.1109/JSYST.2015.2460747 


\section{Copyrights}

Copyright for this article is retained by the author(s), with first publication rights granted to the journal.

This is an open-access article distributed under the terms and conditions of the Creative Commons Attribution license (http://creativecommons.org/licenses/by/4.0/). 